\title{
O COLONATO NA REGIÃO SERRANA FLUMINENSE: CONFLITOS RURAIS, DIREITOS E RESISTÊNCIAS COTIDIANAS
}

Rural work in the highland region of the state of Rio de Janeiro: conflicts, rights and daily resistances

MARCUS DEZEMONE

http://dx.doi.org/10.1590/S0103-21862015000200003

Marcus Dezemone é professor adjunto de História do Brasil República da UFF e professor adjunto de História do Brasil da UERJ (dezemone@gmail.com).

A presente pesquisa contou com o auxílio do CNPq.

Artigo recebido em 30 de junho e aprovado para publicação em 29 de setembro de 2015. 


\title{
Resumo
}

0 artigo analisa o colonato a partir dos conflitos menos visíveis, de menor expressão pública, entre proprietários e trabalhadores da cafeicultura na região serrana fluminense. Na longa duração de fins do século XIX até meados do XX, acompanhamos a construção de noções de direitos e as resistências cotidianas, da gênese até a desagregação do colonato, com o êxodo rural e as lutas pelo acesso à terra. As conclusões permitem compreender melhor processos do mundo rural, como a passagem do trabalho escravo ao livre, a circulação da mão de obra entre propriedades rurais, e as conjunturas de mobilização e desmobilização política.

Palavras-CHAVE: colonato, cafeicultura, conflitos rurais, resistências cotidianas, escravidão, mundo rural.

\begin{abstract}
The article analyzes the experience of rural work named "colonato" in the highlands of the state of Rio de Janeiro by examining conflicts not clearly visible, of little public expression, between landlords and coffee workers. From the late XIXth century until the mid-XXth, it accompanies the construction of the notions of rights and the everyday resistances, from the genesis to the breakdown of the system of "colonato", marked by rural exodus and struggles for access to land. The research allows us to understand processes of the rural world, as the passage of slave labor to free labor, the circulation of workers between farms and the situations of political mobilization and demobilization.
\end{abstract}

KeYwORDs: "colonato"; coffee; rural conflicts; daily resistance; slavery; rural world.

\section{RÉSUMÉ}

L'article analyse l'expérience de travail rural qu'on appelle le "colonato" dans la région montagneuse de l'état de Rio de Janeiro à partir de l'examen des conflits moins visibles, de peu d'expression publique, entre propriétaires et travailleurs de la culture du café. De la fin du XIXe siècle jusqu'au milieu du XXe on accompagne la construction des notions de droits et les résistances quotidiennes, depuis la genèse jusqu'à la fin de l'expérience du "colonato", provoquée par l'exode rural et les luttes pour l'accès à la terre. Les conclusions nous permettent de mieux comprendre les processus du monde rural, comme le passage du travail esclave au travail libre, la circulation des travailleurs entre les fermes et les situations de mobilisation et démobilisation politique.

Mots-CLÉs: "colonato"; café; conflits ruraux; résistance quotidienne; esclavage; monde rural. 


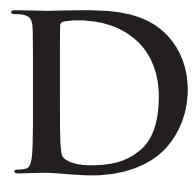

o final do século XIX até meados do século XX, o colonato foi o sistema que predominou na organização do trabalho nas áreas cafeeiras do Sudeste brasileiro. Tal sistema não teve uma história ou trajetória única nas fazendas em que foi adotado. Tampouco deixou de apresentar aspectos comuns, elementos que permitiriam percebê-lo como um conjunto de práticas que se assemelham ao pautar as relações entre proprietários e trabalhadores no campo. Essas relações foram perpassadas por constantes conflitos, que em alguns casos receberam destaque na imprensa, com registros policiais ou processos judiciais, mas em outros permaneceram esquecidos, sem ter alcançado maior expressão pública ou despertado atenção a ponto de se tornarem objeto de reflexão de pesquisadores.

De um modo geral, as análises acadêmicas sobre os conflitos rurais atribuem destaque maior ao que seriam as "grandes mobilizações", as revoluções e revoltas, lutas mais abertas, no sentido de movimentos que alcançaram maior visibilidade, cujo objetivo foi alterar por completo o estado de coisas vigente, substituir ou enfrentar poderes constituídos (cf. Dezemone, 2004). Tais abordagens deixariam de lado, numa posição secundária, ou até mesmo ignorada, as formas de atuação mais comuns do campesinato: aquelas que autores como James Scott (1986) chamaram de "formas de resistência cotidiana".

As resistências do dia a dia devem ser valorizadas para melhor se pensar os conflitos no mundo rural. Entre o sentimento de desconforto com alguma coisa e sua expressão individual ou coletiva há um longo percurso que não necessariamente desemboca numa disputa aberta. A emergência e a transformação de disputas, e como elas se tornam públicas ou não, apontam para a permanência dos conflitos para além dos momentos de mobilização e das lutas mais valorizadas pelos historiadores e cientistas sociais. No dizer de Moacir Palmeira (1979: 41), "o estudo dos conflitos em períodos de desmobilização é fundamental para entender o aparecimento ou desaparecimento de conflitos mais abertos". Além disso, essa escolha permitiria, na ótica de Palmeira, propor um recorte dos fatos alternativo àquele comumente escolhido, pois muitas vezes o recorte tradicional das grandes explosões e movimentos contemplado pelas análises acadêmicas "não é outro que não o dos interessados em esconder a existência de conflitos e tensões de longa data".

Este artigo busca entender como se operou o desenvolvimento de noções de direitos e de resistências cotidianas nos conflitos ocorridos entre proprietários e trabalhadores rurais nos 
processos de gênese, reconfiguração e superação do sistema do colonato. Para isso, foi utilizado um corpus documental relacionado à antiga fazenda cafeeira Santo Inácio, ao município de Trajano de Moraes, que até 1938 se chamava São Francisco de Paula, e à região serrana do estado do Rio de Janeiro.' 0 período cronológico contemplado foi longo: da aquisição da fazenda pela família proprietária, em 1872, quando utilizava mão de obra escrava, passando pela introdução do colonato e pelas redefinições sofridas após a década de 1930, e chegando até a desagregação do sistema na região nas décadas de 1950 e 1960.

A fazenda Santo Inácio foi a única na região serrana que sofreu desapropriação parcial de 1/3 de sua área original para fins de reforma agrária em 1987, fruto de uma longa luta de resistência e permanência na terra. Caso singular, mas que, se tomado de forma não teleológica e em relação com as demais fazendas da região, pode ajudar a pensar as ocasiões em que o colonato foi encerrado sem produzir os mesmos resultados. Desse modo, adotou-se procedimento de pesquisa próximo ao da experiência da micro-história (Revel, 1998). As questões investigadas não se esgotaram nos limites da fazenda, do município ou da região. A perspectiva assumida é de que o "micro" permite construir objetos complexos e revestidos de múltiplas dimensões sociais. Trata-se de pensar de forma comparativa a fim de evidenciar padrões no sistema do colonato, permitindo uma melhor compreensão dessa relação social, e de contribuir para repensar, a partir de suas particularidades, os modelos de análise existentes, muitos consagrados por uma historiografia tradicional. Casos específicos, aprofundados e bem estudados, podem fornecer indicações universais e contribuir para redefinir padrões e modelos interpretativos.

A fim de cobrir um recorte cronológico tão extenso, a investigação se concentrou em três momentos analíticos definidos pelos relatos de pessoas envolvidas nesses conflitos:

1. A passagem da mão de obra escrava para a livre na origem do sistema do colonato, em fins do século XIX;

2. Os efeitos da "dupla crise" - a Crise de 1929 e a Revolução de 1930 - no campo, conduzindo a alterações no sistema;

3. O avanço da pecuária e a erosão da autoridade tradicional dos fazendeiros, que resultaram em reações diferenciadas, como a tentativa de reinserção dos trabalhadores em novas fazendas, o êxodo rural e as lutas sociais.

Dessa maneira, foram identificados elementos que sugerem tanto a relativização de teses consagradas pela produção acadêmica quanto a complementaridade de recentes linhas historiográficas: a contribuição de práticas surgidas no cativeiro para o colonato, os efeitos 
da circulação da mão de obra pelas fazendas da região, e as conjunturas de mobilização e desmobilização política.

\section{A EMERGÊNCIA DO COLONATO: UM "CONTRATO SOCIAL IMPLÍCITO"}

$\mathrm{F}$ oi como solução para a manutenção e expansão da atividade cafeeira que o colonato se desenvolveu durante a crise do escravismo e após o fim da escravidão, tornando-se o sistema de exploração que organizou a força de trabalho na fazenda Santo Inácio, na região serrana fluminense e no Sudeste cafeeiro. Na passagem do século XIX para o XX, essa região encontrava-se no seu auge produtivo, contrastando com o Vale do Paraíba, considerado em declínio, e o Norte Fluminense, área recente e ainda aberta à expansão (Melo, 1996).

0 sistema baseava-se em três pilares. 0 primeiro era o controle da terra pelos fazendeiros através da propriedade privada, reconhecida pelo Estado e por outros atores, entre os quais os colonos (Martins, 1979). A propriedade privada, mesmo quando obtida de forma escusa e por meios ilícitos, conferia aos fazendeiros o poder de império, isto é, de dispor do uso da terra da maneira que julgassem adequada. ${ }^{2} \mathrm{~A}$ história do colonato também poderia ser contada por meio das limitações impostas a esse poder, que tinha uma dimensão não apenas jurídica ou econômica, mas também moral, o que fazia com que o proprietário, além de "dono", fosse "patrão". 0 segundo pilar do colonato foi o uso da mão de obra juridicamente livre que, ao contrário da mão de obra cativa, teria como possibilidade mais tangível - embora não isenta de implicações - a opção pelo abandono da propriedade (Stolcke \& Hall, 1983). Por fim, as condições da agricultura em geral e da atividade cafeeira em particular, que viabilizavam a manutenção e reprodução do sistema enquanto este assegurasse retornos materiais e simbólicos considerados satisfatórios tanto pelos proprietários de terras quanto pela mão de obra, mesmo que julgados em parâmetros diferentes (Garcia \& Palmeira, 2000). Por tudo isso, os trabalhadores sob o colonato encontravam-se numa "condição camponesa tutelada" (Neves, 2008).

A viabilidade econômica da produção com mercados compradores e condições naturais propícias à cafeicultura não dispensou a adaptação à força de trabalho livre. Não foi um processo sem conflitos e tensões, que teria engendrado automaticamente regras, combinações, obrigações recíprocas envolvendo proprietários e trabalhadores. As estipulações foram estabelecidas por meio de recuos e avanços, com negociações entre as partes envolvidas. Isso não quer dizer que os termos dessas negociações foram iguais para fazendeiros e colonos. A balança desigual de poder entre proprietários e não-proprietários impunha limites às negociações, moldando e definindo o colonato. Mas havia uma margem entre os negociantes e, por menor que esta possa ter sido, serviu para pactuar o que seria permitido dentro da relação 
Nisso, teríamos o que Barrington Moore Jr. (1987) chama de um "contrato social implícito", no qual seriam "negociados" os alcances e os limites da dominação nas relações entre partes assimétricas. A proposta de Moore Jr. serve para estudar as negociações entre fazendeiros e mão de obra nos termos integrantes do sistema de colonato. Trata-se de pensá-lo como um "contrato" que pode sofrer alterações ao longo do tempo, ser modificado ou rompido. 0 que se procura perceber é como se opera a elaboração e a ruptura dos termos desse "contrato", ressalta-se, entre partes que não se percebem como iguais, mas que, em maior ou menor medida, dependeram (e precisaram) uma da outra.

Quem desejasse trabalhar numa fazenda só poderia se tornar colono com o aceite do administrador, que representava o fazendeiro. 0 colono não deve ser confundido com outros trabalhadores rurais empregados como 'campeiros' (que ordenhavam as vacas); 'tropeiros' (guiavam as tropas); 'carreiros' (conduziam o carro de boi) e 'candeeiros' (ajudantes de carreiros). Caso a permissão fosse concedida, o colono recebia uma casa para residir, plantar para si e para sua família. Isso era percebido pelo colono como uma concessão do fazendeiro, uma contrapartida inicial, que demandaria, e até mesmo exigiria obrigações. 0 recebimento da casa trazia consigo a noção de que a condição da moradia estava associada à prestação de trabalho. Moacir Palmeira (1977) revelou que a mesma lógica unia moradia e trabalho nos engenhos do Nordeste.

Os espaços que integravam o sítio dos colonos - a casa, o terreiro e a roça -, além do fato de o empregado não receber sítio e sim casa com terreiro sem direito a roça, seriam, em linhas gerais, mantidos ao longo da trajetória do sistema de colonato do final do século XIX até o seu ocaso. Contudo, as "obrigações" prestadas pelos colonos sofreram alterações.

A primeira "obrigação" do colono na região serrana era a meia, que correspondia à entrega ao fazendeiro de metade da colheita de café produzida no sítio. A segunda era o trabalho nas terras e lavouras da fazenda nas turmas, compulsórias e não remuneradas. 0 colono teria que, duas vezes por semana, contribuir com atividades de preparação, plantio, trato, colheita, transporte e secagem do café nas terras da fazenda, que não seriam terras do sítio. As turmas assemelhavam-se ao cambão da Zona da Mata de Pernambuco, que foi descrito em detalhes por Francisco Julião e consistia no trabalho gratuito e necessário do morador como condição para sua permanência num engenho. Ambos - cambão e turmas - compunham a lucratividade dos proprietários, que dispunham de trabalho sem ônus monetário. Trabalho excedente, além dos dias obrigatórios, seria pago por meio da diária, que poderia servir ao colono para ganhos em momentos de necessidade. A entrega da meia e o trabalho nas turmas eram fiscalizados pelo administrador, que prestava contas ao fazendeiro e verificava o cumprimento das obrigações pelos colonos. A renda era mais uma "obrigação" do sistema. Nela, 
se entregava nas fazendas da região, variando produto e percentual, entre $10 \%$ e $20 \%$ dos demais cultivos (Dezemone, 2008 a: 121-123).

A comparação do sistema do colonato com o sistema da morada na Zona da Mata de Pernambuco revela diferenças interessantes. Segundo Beatriz Heredia (1979), a autorização para o morador plantar em seu sítio lavouras para a comercialização dependia diretamente da permissão do proprietário. Para obtê-la, o morador competia com outros moradores buscando o melhor cumprimento das obrigações para com a fazenda. Desse modo ele poderia receber o aval do administrador do engenho, que avisaria ao proprietário. Após a permissão do patrão para tocar seu próprio sítio, o morador dedicava-se com mais afinco ao roçado nas terras do engenho, o que era explicado pelo desejo de "retribuir a confiança do patrão". Ao contrário da morada do Nordeste, na região serrana fluminense, a possibilidade de plantio e comercialização das lavouras de subsistência no sítio foi um termo integrante da relação de colonato desde sua origem. Cabe entender como e por quê.

\section{A gênese do ColonAto: CATIVEIRo, FAMÍlia E CULTIVOS DE SUSBSISTÊNCIA}

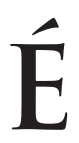
comum associar o colonato a práticas e costumes ligados à introdução da mão de obra imigrante de origem europeia (Stein, 1990; Dean, 1977; Martins, 1979; Stolcke, 1986). Parte da produção acadêmica reforça isso ao corroborar um conjunto de teses clássicas a respeito do papel do fim da escravidão na atividade cafeeira e na agricultura fluminense: o final do século XIX e início do XX teriam correspondido à "estagnação" e ao "declínio" da agricultura local a partir da "crise do café" e do esvaziamento econômico das fazendas do Vale do Paraíba em benefício da região do Oeste Paulista (Fausto, 1986). Essa interpretação ecoa a perspectiva dos proprietários rurais e descrições como a de Monteiro Lobato, que abordou a passagem das "ondas verdes", que transformaram o ambiente social do antes próspero Vale do Paraíba em "cidades mortas".

A "decadência" estaria relacionada aos efeitos decorrentes da Lei Áurea de 1888, que, ao emancipar os escravos sem indenizações aos proprietários, teria levado à perda dos recursos imobilizados na aquisição da mão de obra. Além disso, essas leituras insistem que a maior parte dos libertos abandonou as fazendas fluminenses em direção às cidades, ajudando na falência dos proprietários rurais que insistiram na cafeicultura (Fausto, 1986). Essas representações conduzem a dois desdobramentos: potencializar a responsabilidade dos ex-escravos no declínio material dos proprietários rurais e minimizar a participação dos libertos com a Abolição nas origens do colonato. 
Numa outra direção, estudos sobre o campo fluminense abrem uma nova possibilidade investigativa: apesar de os trabalhos não falarem em um dinamismo da agricultura, eles permitem apontar elementos que demonstram insuficiências nas teses da "estagnação" e da "decadência" (Dezemone, 2008 a: 53-55). É quase impossível identificar com precisão quantos libertos abandonaram ou permaneceram nas fazendas da região serrana fluminense após o Treze de Maio. As séries históricas com os dados demográficos não ajudam muito. Pelos indicadores disponíveis, de 1872 a 1920, a freguesia e depois município de São Francisco de Paula, nas duas últimas décadas do século XIX, teve como principal alteração o aumento percentual do número de mulheres no conjunto da população, sem ter modificado profundamente a distribuição dos grupos de cor indicada em 1872. Acompanhado do aumento dos matrimônios, isso pode indicar a formação de grupos familiares mais estáveis. Ainda que em seu surgimento, no final do século XIX, o colonato tivesse recebido indivíduos provenientes de diferentes origens sociais, com trajetórias de vida distintas, como homens livres pobres e imigrantes europeus, o perfil demográfico em 1920 era o de uma população predominante de pretos e pardos, o que sugere a presença de descendentes de escravos (Dezemone, 2008 a). ${ }^{3}$

Com base no cruzamento das fontes - dados censitários, registros de batismos e de matrimônio - constata-se que a saída de ex-cativos e a chegada de imigrantes não aconteceram de forma automática logo após a Abolição. No mínimo, elas se estenderam lentamente de 1892 até 1900, quando a escassez de braços para a expansão da atividade cafeeira mostrou-se um problema relevante. A intensificação da presença imigrante aconteceria somente após 1900, sobretudo depois de 1910. Não parece, por maior que tenha sido a taxa de fecundidade dos estrangeiros, que esse grupo tenha sido o único responsável pela recuperação demográfica sugerida pela confrontação dos censos de 1900 (7.620) e 1920 (22.221). Fica evidente, analisando-se registros de batismo, que nacionais contribuíram para o aumento populacional (Dezemone, 2008 a: 56-58).

Além do aspecto demográfico, as combinações relacionadas ao colonato revelam vínculos ainda mais consistentes com a escravidão. Um dos aspectos mais importantes é o plantio de cultivos de subsistência, naquilo que Ciro Cardoso (1987) difundiu através da expressão "brecha camponesa" - 0 acesso dos escravos a lavouras alimentares para consumo próprio e até mesmo comercialização. Para João José Reis e Eduardo Silva (1998), a "brecha" seria "outro mecanismo de controle e manutenção da ordem escravista". Segundo os autores, "ao ceder um pedaço de terra em usufruto e a folga semanal para trabalhá-la, o senhor aumentava a quantidade de gêneros disponíveis para alimentar a escravatura numerosa, ao mesmo tempo em que fornecia uma válvula de escape para as pressões resultantes da escravidão". Robert Slenes (1999) fez uma crítica à expressão, afirmando que ela pode reduzir a dimensão do conflito e da tensão 
entre escravos e senhores, preferindo entender que o acesso a cultivos de subsistência faz parte de uma "economia interna dos escravos", termo que aparece na historiografia americana e que realça a disputa e a luta para a obtenção do plantio e do comércio dos cultivos.

Independentemente da interpretação que se escolha, o desejo dos escravos de acesso a atividades de subsistência é bem antigo, como revela conhecido documento datado de 1789: o tratado proposto a Manoel da Silva Ferreira pelos seus escravos durante o tempo em que se conservaram levantados na fazenda Santana, em Ilhéus, na Bahia. Nele, lê-se a reivindicação dos escravos revoltosos: "Em cada semana nos há de dar os dias de sexta-feira e de sábado para trabalharmos para nós não tirando um desses dias por causa de dia Santo e para podermos viver nos há de dar uma rede, tarrafa e canoas" (apud Alves Filho, 1999: 131). Em 1847, Francisco Peixoto de Lacerda Werneck, o Barão de Paty do Alferes, aconselhava os que desejassem montar uma fazenda cafeeira:

"o mais próximo que for possível, reservar um bocado de terra onde os pretos façam as suas roças, plantem o seu café, o seu milho, feijão, banana, batata, cará, aipim, cana etc. Não se deveria porém consentir que a colheita [dos escravos] seja vendida a outrem, e sim ao seu senhor, que deve fielmente pagar-Ihe por um preço razoável, isto para evitar extravios e súcias de tabernas. (...) Estas suas roças, e o produto que delas tiram, fazem-Ihes adquirir um certo amor ao país, distraí-los um pouco da escravidão e entreter o seu pequeno direito de propriedade. (...) 0 extremo aperreamento desseca-Ihes o coração, endurece-os e inclina-os para o mal".

Presente nas indicações fornecidas por escravos e senhores, em que pese a visão restritiva dos historiadores, a "brecha camponesa" teria sido alargada nos anos finais da escravidão e na passagem para o trabalho livre. Reforça isso a indicação de Arrigo de Zetirry, funcionário do governo italiano que produziu, de julho de 1894 a janeiro de 1895, uma série de 21 reportagens para o Jornal do Comércio. Intitulada "A Lavora no Estado do Rio", nela ele descreveu suas visitas às fazendas da região norte fluminense, anotando minuciosamente características das propriedades no pós-Abolição. ${ }^{4}$

Nas reportagens nota-se boa presença de libertos organizados em famílias na lavoura na região. Hildete Pereira de Melo (1996: 230) considera que, "pelo relato de Zetirry, infere-se que $50 \%$ dos trabalhadores eram de famílias de libertos (...) o que devemos fixar foi que ex-escravos e roceiros pobres constituíram a massa de trabalhadores do Estado do Rio de Janeiro". Hebe Mattos (1998), baseando-se no italiano, notou que a retribuição dos trabalhadores era associada à formação dos cafezais, onde, junto com suas famílias, moravam nas fazendas e podiam plantar milho e feijão, tanto em terrenos separados quanto em fileiras intercaladas pelo café. A descrição coincide exatamente com as características do colonato na fazenda Santo Inácio e na região. 
As indicações de Zetirry também ajudam a entender outro fenômeno curioso que aconteceu na região após o Treze de Maio: a explosão de matrimônios coletivos de libertos celebrados nas igrejas, com mais de 5 casamentos no mesmo dia, lançados nos mesmos assentamentos, com os casais listados em sequência, como asseguram as mesmas testemunhas, muitas das quais ex-senhores. ${ }^{5}$ Apenas na freguesia de São Francisco de Paula, no período de 1888 a 1892, que vai da Abolição até as vésperas do primeiro registro de casamento de imigrantes espanhóis em 1893, ocorreram 42 cerimônias coletivas de matrimônio de libertos. Foi contabilizada a união de 800 libertos, a maioria dos quais pertencera a senhores de grandes plantéis, com mais de 20 escravos. As uniões se concentraram em 1888, quando aconteceram 30 dos 40 casamentos coletivos, reunindo 662 libertos.

Em Cordeiro, à época freguesia de Cantagalo e vizinha de São Francisco de Paula, Zetirry entrevistou Francisco Constantino, liberto e colono. Constantino disse-lhe em janeiro de 1895 que "casei há três meses com a mulher que sempre viveu comigo, deu-me oito filhos e sempre foi muito direita e levou tudo muito em regra. Não posso queixar-me della" (Jornal do Comércio, 14/01/1895).

No pós-Abolição, as uniões de facto estavam sendo reconhecidas na Igreja, num claro indício de formação de famílias que se aproximava da mais concreta experiência de liberdade ao alcance dos libertos: a de homens livres pobres (Mattos, 1998). 0 modelo, gestado sob a escravidão, caracterizava-se pelo trabalho familiar, acesso a lotes com cultivos de subsistência e venda de parte da produção. Foi dessa forma que uma das contrapartidas para a permanência de libertos nas fazendas passou pelo acesso aos cultivos de subsistência (milho e feijão) com base no trabalho familiar. Essas mesmas condições para a permanência de libertos foram notadas em outras fazendas do Sudeste no pós-Abolição (Rios \& Mattos, 2005).

0 que Arrigo de Zetirry registrou poucos anos após a emancipação e apareceu nos depoimentos orais de ex-colonos são duas noções que caminharam juntas - acesso aos cultivos de subsistência e produção familiar, direitos que acompanharam toda a trajetória do colonato.

Além desses direitos, os depoimentos de ex-colonos realçaram outros elementos de continuidade com o passado escravista. O Sr. Juscelino Cândido, mais conhecido como Sr. Binó, descendente de escravos que ainda vivia na fazenda Santo Inácio em 2001, sintetizou isso: "O cativeiro, quando acabou, o fazendeiro ficou com aquela catinga do cativeiro ainda". Indagado sobre o que era a "catinga do cativeiro", ele explicou:

"Sabe por quê? Camarada não tinha liberdade. Camarada segunda-feira não tivesse na turma - a turma era segunda e terça -, camarada não tivesse na turma, se ele não fosse... Aí mandava 
chamar o coronel na fazenda. [Faltava] bater no colono porque ele não faz pagar um dia de turma. Se fosse preciso faltar um dia de turma, ele ia na Casa, tinha que vir na fazenda comunicar por que ele deixou de pagar aquele dia de turma". ${ }^{6}$

0 tratamento conferido aos trabalhadores juridicamente livres em bases semelhantes ao cativeiro teria gerado conflitos. Nesse sentido, o Sr. Binó falou da expulsão de seu padrasto da Santo Inácio: "Eu era pequeno, meu padrasto foi mandado embora da fazenda Santo Inácio (...), com 24 horas", esclarecendo em seguida o significado disso:

"Era a lei deles. Se um camarada não desocupasse com 24 horas, amanhã ele mandava o cara subir aqui, tirar a telha da casa, que o camarada ficava no tempo de qualquer maneira. 0 fazendeiro mandava o cara vir tirar a telha da casa [para o] camarada sair mais depressa, se não saísse com 24 horas".

A dispensa era algo comum no colonato. Se o prazo exíguo não fosse obedecido, ocorreria a retirada das telhas da casa do colono. Assim, a expulsão significava a prevalência do desejo e do poder pessoal dos proprietários ou prepostos. Por isso, frisa-se, o Sr. Binó fala na "lei deles".

As 24 horas e a retirada das telhas, comuns nas fazendas da região, encerravam o contrato social implícito, sem ressarcimento ou indenização de qualquer natureza pelo trabalho e pelas benfeitorias do colono. Essas práticas marcavam ainda, na ótica dos colonos, a permanência do cativeiro para além do marco legal da Lei Áurea, diferente dos marcos políticos tradicionais e da própria percepção da escravidão.

\section{Conflitos E CiRCUlação PELAS FAZENDAS DA REGĩ̃o}

parentemente, os conflitos nas saídas das fazendas na primeira metade do século XX
tiveram menor destaque quando comparados às mobilizações nos anos 1960, que ocuparam grande espaço nos periódicos e nos registros da polícia, com resistências às expulsões (Grynszpan \& Dezemone, 2007). Cabe entender por quê. Nesse sentido, um trecho que à primeira vista poderia ser considerado sem relevância no depoimento do Sr. Binó, ao ser pensado com um pouco mais de cuidado, sugere a existência de um arranjo que teria permitido a menor visibilidade daqueles conflitos: "Mas então, naquele tempo, em qualquer fazenda você encontrava uma casa, qualquer fazenda. E o meu padrasto foi despedido, com 24 horas (...) naquela época o pobre achava casa pra morar".

Quando o Sr. Binó falou da expulsão de seu padrasto da fazenda Santo Inácio e de seu ingresso na fazenda das Neves, o motivo foi minimizado no relato em virtude da facilidade de 
obtenção de "casa pra morar". Uma interpretação ligeira consideraria "morar" como sinônimo de habitar, sentido urbano atribuído ao verbo. Contudo, para os colonos da região serrana, "morar" associa, necessariamente, trabalho e residência numa fazenda. Para o ex-colono, a catinga do cativeiro e as 24 horas situavam-se numa época na qual eram encontrados trabaIho e moradia combinados, o que em dado momento deixaria de acontecer.

Na sequência do seu depoimento, o ex-colono afirmou que após a expulsão a família foi para a fazenda das Neves e, "depois, eu me enjoei, saí da fazenda das Neves; da Piedade, fui pra fazenda das Neves. (...) Aí eu vim pra aqui [Santo Inácio], pedi uma casa pra mim pro Antônio Cordeiro, o administrador que morreu há pouco tempo." Outro ex-colono resume sua trajetória após a saída de Valão do Barro com a passagem pelo trabalho na lavoura da cana: "trabalhei na usina uns tempos mas depois saí. Depois eu quis voltar pra Valão do Barro pra tratar da lavoura. Então fui aonde estava o português. Eu fui pra lá e pedi a ele se ele me dava um lugarzinho pra fazer lavoura", para somente depois seguir para Trajano de Moraes. Esse modelo se repete em diversos depoimentos. ${ }^{7} 0$ que se defende é que um dos fatores que contribuíram para a circunscrição dos conflitos e sua menor visibilidade na primeira metade do século XX foi a constatação de uma intensa circulação da mão de obra pelas fazendas da região.

Seja por motivo voluntário, seja pelas expulsões, quando saídos de uma propriedade, os camponeses encontravam abrigo noutra fazenda, recebendo obrigações (iguais ou com variações) e prestações de natureza pessoal diante de outro fazendeiro ou administrador. Deve ser enfatizado que não eram todos os colonos expulsos de uma fazenda que conseguiam entrada imediata em outra após a saída, embora os depoimentos orais coletados sempre afirmem isso. Esse tipo de representação deve ser encarado como uma possibilidade de entrada nas fazendas. Esse mecanismo de circulação pelas fazendas mantinha estável o grupo de dependentes dos proprietários, assegurava clientela política aos últimos e permitia a reprodução de um modo de vida camponês aos trabalhadores.

A circulação pelas fazendas da região ajudaria a compreender por que os conflitos naquela conjuntura não ganharam destaque e engendraram atos de resistência como na década de 1960. 0 que estava em jogo na estratégia dos colonos era manter o modo de vida camponês, afastando-se de alternativas mais traumáticas, como a do êxodo rural ou a da resistência pública. Soma-se a isso a ausência de militantes políticos que poderiam estimular enfrentamentos e que só atuariam com maior presença na região na década de 1960 (Dezemone, 2008 a). Mas não foi só a presença desses militantes que promoveu as lutas. Eles atuaram a partir de um conjunto de noções de direitos que foram, de forma aparentemente contraditória, desenvolvidas num período de aumento do controle e da exploração dos colonos por parte dos proprietários. 


\section{A DUPLA CRISE E AS NOÇÕES DE DIREITOS, JUSTIÇA E LEGALIDADE}

década de 1930 foi uma época conturbada no mundo rural brasileiro, tanto para pro-
prietários quanto para colonos. Eles viveram os desdobramentos da dupla crise - econômica com a Crise de 1929 e política com a Revolução de 1930 - que inaugurou alterações nos anos seguintes.

A Crise de 1929 gerou acentuada queda no preço dos gêneros agrícolas em escala mundial. No Brasil, as áreas voltadas para a lavoura de exportação foram seriamente atingidas, como aconteceu com a Zona da Mata Pernambucana, dedicada à produção canavieira. O setor cafeeiro, responsável pelo principal produto de exportação do país, atravessou grave crise quando muitas fazendas foram à falência (Garcia \& Palmeira, 2000). A Revolução de 1930 promoveu cassações de mandatos e nomeações de interventores estaduais, com mudanças que levaram ao deslocamento do eixo político fluminense da região cafeeira para o norte do estado. Isso acarretou perda de influência e prestígio dos cafeicultores em benefício dos grandes plantadores de cana-de-açúcar.

As fazendas da região serrana tornaram-se cada vez menos rentáveis e produtivas. De 1920 a 1940, a produção de café do município de São Francisco de Paula sofreu redução de $34 \%$. No mesmo período, a produção bovina aumentou $45 \%$. Quando se compara a evolução das áreas dedicadas à pecuária e aquelas dedicadas às demais lavouras, incluindo o café, entre os anos de 1940 e 1960, constata-se que, de 32\% das áreas ocupadas pela pecuária em 1940, salta-se para 43\% em 1950, chegando-se a 45\% em 1960. Enquanto isso, as áreas ocupadas por lavouras, que em 1940 correspondiam a $26 \%$ do total, diminuem para $20 \%$ em 1950 e 17\% em 1960. 0 aumento das áreas das terras voltadas para a pecuária se deu com 0 avanço diante das áreas que se dedicavam aos demais cultivos, sobretudo o café, mas não exclusivamente: os cultivos alimentares também foram atingidos. Ao avanço da pecuária correspondeu uma diminuição da população total, que caiu de 22.221 habitantes em 1920 para 16.771 em 1950 em meio à intensificação da urbanização. ${ }^{8}$

Os abalos sofridos a partir de 1930 não acabaram com a dedicação à grande plantação cafeeira, mas alteraram as bases do colonato, o que permitiu aos proprietários atravessar a dupla crise, com novo impulso para a manutenção do sistema por pelo menos mais 20-30 anos. Entre as novas bases do contrato social implícito elaborado na fazenda Santo Inácio, os relatos mencionam uma venda - depósito e armazém onde os colonos adquiriam produtos. A venda guardava semelhanças com o barracão, existente na Zona da Mata Pernambucana, cuja lógica foi investigada por Moacir Palmeira (1977). Na venda, os fazendeiros disponibili- 
zavam para os colonos itens de primeira necessidade, instrumentos de trabalho, remédios e outros produtos que, pela distância, dificilmente poderiam ser adquiridos em outros lugares. No entanto, as compras não envolviam cédulas da moeda corrente, e sim cupons (no Nordeste eram os vales) que registravam o nome do comprador, o produto e o preço. No acerto do pagamento dos colonos pela colheita do café, o fazendeiro ou o administrador abatia o total dos cupons de cada colono. Na prática, isso invertia a relação de pagamento, resultando no endividamento dos colonos diante dos fazendeiros.

Além da venda, outra mudança foi a introdução de novas obrigações, como se percebe pelo "regulamento" dos colonos da fazenda, que constava na contracapa das cadernetas dos anos 1930. 0 regulamento apresentava as "obrigações a que estão sujeitos os colonos das Fazendas: S. Inácio, Monte Claro, Barro Alto e Retiro". ${ }^{9}$ Junto da entrega da metade da produção de café na meia, os cultivos de subsistência como o feijão e o milho passaram a constar das obrigações do colono através da renda, conforme o artigo $2^{\circ}$ do regulamento: "da colheita de milho e feijão que o colono produzir, dará à fazenda a quota de 10\%". 0 direito aos cultivos alimentares para consumo e comercialização herdado do cativeiro seria mantido, porém com limitações. No artigo $4^{\circ}$ constava que "qualquer movimento de mercadorias do colono só poderá ser feito pelos carros ou tropa da fazenda", numa clara medida para controlar a comercialização dos cultivos que passaram a integrar a renda.

As restrições constantes na caderneta apareciam quando se avisava que "o colono não poderá trabalhar fora da fazenda", conforme 0 artigo $8^{\circ}, 0$ que ampliaria a dependência de uma única fonte de renda. Ao mesmo tempo, no artigo $7^{\circ}$, havia a intenção de garantir a disponibilidade da mão de obra quando necessário: "o colono não poderá se negar a qualquer chamado para turma ou auxílio à fazenda". A tentativa de assegurar a sujeição dos trabalhadores diante do fazendeiro constava no artigo $5^{\circ}$, no qual "as benfeitorias, como cerca, paiol, galinheiro, etc., que o colono fizer, não poderão ser arrancadas ou destruídas por este, independente de indenização pela fazenda". Até um "imposto" seria devido: "o colono pagará por ano, a título de imposto, a quantia de $15 \$ 000^{\prime \prime}$, registrava o artigo $9^{\circ}$.

0 regulamento nas cadernetas não foi determinado por nenhuma legislação, sendo um documento de natureza privada, que fixava por escrito as obrigações de ambas as partes no colonato. A leitura do regulamento sugere o desejo dos proprietários na imposição de mecanismos de controle sobre os colonos, gerando aumento da dependência deles e da exploração numa conjuntura de crise. Sugere ainda que, se os colonos cumprissem todas as obrigações determinadas, não haveria necessidade de escrevê-las nas cadernetas. A fixação das normas indica que as combinações poderiam estar sendo burladas por ações de resistência cotidiana. Exemplifica isso a proibição da destruição de benfeitorias em caso da 
saída dos colonos: se não estivessem acontecendo, não haveria porque fazê-las constar no regulamento.

De modo aparentemente paradoxal, num período que poderia estar associado a perdas materiais e piora nas condições de vida, emerge um lugar privilegiado para Getúlio Vargas, a legislação trabalhista e direitos. Nas palavras do Sr. Binó:

"Quer dizer, não tinha governo, não tinha nada. Quer dizer, isso taí, agradeço ao governador que morreu: Getúlio Vargas! Ele que deixou essa aventurança. Porque antes dele morrer, ele deixou isso aqui. Ele fez um livro e deixou tudo isso escrito. Se falaram em Reforma Agrária, se falaram em salário mínimo, foi antes dele morrer. (...). Mas naquele tempo [de Washington Luís] o pobre não tinha direito".

0 presidente figura nos relatos associado a direitos e leis, enquanto épocas anteriores eram percebidas como de arbítrio, catinga do cativeiro, 24 horas e injustiça. Essa visão positiva de Vargas aparece de forma generalizada no mundo rural brasileiro, contrariando a historiografia majoritária que insiste num fosso afastando os trabalhadores rurais dos benefícios materiais e simbólicos da legislação social. Houve, sem dúvida, uma apropriação camponesa do discurso oficial e da legislação social produzida e divulgada principalmente no Estado Novo (Dezemone, 2008 b).

Camponeses em todo Brasil utilizaram o discurso paternalista e a imagem do presidente poderoso e corajoso para reivindicar aquilo que interpretavam como justo, seja remetendo cartas com pedidos a autoridades, seja entrando com ações na Justiça Comum ou na Justiça do Trabalho. Também na memória dos colonos, Getúlio Vargas era detentor de um poder superior ao dos fazendeiros, alguém diretamente responsável pela limitação da autoridade e das formas de dominação dos grandes proprietários, que agora poderiam encontrar um obstáculo na força moral da imagem do presidente associado a leis. Compreende-se melhor, assim, a construção social do "legalismo" tão frequentemente atribuído aos trabalhadores do campo, naturalizado por inúmeros militantes políticos como Francisco Julião, para quem "o camponês é muito legalista" (Dezemone, 2008 b: 234).

\section{A EROSÃo do COLONATO E O FIM DA CIRCULAÇÃO PELAS FAZENDAS DA REGIÃO}

substituição dos cafezais pela pecuária foi amplamente difundida na região a partir de
1930, entre outras razões devido ao intuito de assegurar a legitimidade da posse de grandes áreas pelos proprietários tradicionais. Esse processo seguia um padrão: os fazendeiros colocavam o rebanho para pastar nas roças dos colonos, destruindo-as. Como desdobramento 
dessa prática, destaca-se a desagregação das relações de colonato, levando a uma grande quantidade de trabalhadores rurais que não foram absorvidos pela pecuária. Os antigos colonos, agora desempregados, se viram obrigados em sua maioria a migrar para as cidades.

Os relatos orais dos que permaneceram na região evocam, no entanto, um período de constantes boicotes aos dias de trabalho nas turmas e ao pagamento da meia e da renda, revelando a erosão das formas tradicionais de dominação pessoal dos fazendeiros, que não mais se impunham como no passado. Novamente, nas palavras do Sr. Binó:

“No tempo do café havia a meia do café. E não havia nenhuma contribuição do colono pela lavoura branca. Acontece que o café acabou e ficou só a lavoura branca. (...) Algum tempo [os colonos] deram, depois pararam de dar. E como a banana não estava na combinação, todo mundo passou a só plantar banana".

A banana, definida legalmente como "bem de raiz", aumentava os valores das indenizações por benfeitorias em caso de despejo, conforme estipulado no Código Civil de 1916. De 1950 a 1970 houve um aumento de $460 \%$ no plantio de banana no município. ${ }^{10}$

Em meio a essas mudanças, a mais significativa alteração no início da década de 1960, para colonos e fazendeiros, foi o fim da circulação nas fazendas da região. Em Trajano de Moraes, os antigos colonos, desocupados em consequência da substituição dos cafezais pela pecuária, não mais conseguiam abrigo em outras fazendas, conforme percebido pela análise dos depoimentos orais. Foi enquanto possibilidade que a saída/entrada de fazendas se viu encerrada na década de 1960 . 0 ponto central é que era exatamente essa a alternativa que permitia a manutenção do modo de vida dos colonos, que firmavam novos contratos com outros fazendeiros e permaneciam no campo. A redução da população do município, que em 1960 era de 15.821 habitantes, para 12.738 em 1970, foi de 19\% em um decênio. A variável do crescimento da população residente na região foi negativa. ${ }^{11}$

Os conflitos entre trabalhadores rurais e proprietários aumentavam e ganhavam visibilidade na imprensa e na polícia na medida que os primeiros se recusavam a deixar seus sítios. 0 delegado local descreveu tudo isso como a "rota da subversão". ${ }^{12}$ Alguns decidiram permanecer na terra, resistindo nos lotes que já ocupavam, intensificando o plantio de banana para comercialização.

As resistências cotidianas com a permanência na terra diante do avanço da pecuária, os boicotes às obrigações do colonato e o plantio da banana são fundamentais para entender a criação do Sindicato dos Trabalhadores Rurais de Trajano de Moraes (STR). A numerosa participação de colonos da fazenda Santo Inácio, em comparação com os trabalhadores de outras fazendas da região, foi possível pela permanência deles na terra e pelo desgaste da domina- 
ção tradicional do fazendeiro, contrário à organização sindical. ${ }^{13}$ Oficializado em janeiro de 1964, o STR contou com militantes do PCB (Partido Comunista Brasileiro) e com ferroviários, num contexto de competição pela organização dos trabalhadores no campo (cf. Grynszpan \& Dezemone, 2007). Com o golpe miltar, o STR foi fechado e suas lideranças foram presas.

A reabertura do STR ocorreria na década de 1970 em função da proposta do governo de extensão dos direitos sociais ao campo, sobretudo a previdência social, pois o sindicato seria o órgão responsável pela implementação da aposentadoria rural. Nessa ocasião, muitos ex-colonos da fazenda Santo Inácio teriam apoio do STR e de outras entidades para organizar uma estratégia de resistência e permanência na terra, mobilizando as noções de direitos construídas durante o colonato - trabalho familiar, acesso aos cultivos de subsistência, 0 papel das leis, o trabalho na terra -, o que contribuiu para a desapropriação obtida em 1987 (Dezemone, 2008 a).

\section{CONSIDERAÇÕES FINAIS}

trajetória da fazenda Santo Inácio articulada à região serrana, na longa duração que
vai da escravidão à desapropriação, pode auxiliar uma melhor compreensão do sistema do colonato. Seja no acesso familiar aos cultivos de subsistência, na memória sobre Vargas ou nos boicotes às obrigações como meia, renda e turmas, o que há em comum em tais práticas é que elas se fundamentaram, em maior ou menor grau, em conceitos de justiça e injustiça, legitimidade e ilegitimidade, o que indica a gestação de noções de direitos. Mais do que isso: tais práticas permitem perceber como homens e mulheres atuaram explorando brechas, margens e limites, valendo-se de circunstâncias históricas que Ihes pareciam desfavoráveis, mas buscando operá-las em seu favor.

A redução da escala de análise permitiu articular conflitos menos visíveis e formas de resistência cotidiana, acompanhando as alterações nas relações entre proprietários e mão de obra. Tomando a região serrana fluminense como um ponto de partida, foi possível lançar luz sobre os conflitos que tiveram menor visibilidade na região e entender por que determinadas tensões não alcançaram a mesma amplitude daquelas dos anos 1960 e 1970 protagonizadas na Santo Inácio. Dessa maneira a circulação pelas fazendas da região e sua interrupção é um elemento importante para compreender a projeção alcançada pelos conflitos.

A opção pelos conflitos menos perceptíveis não significa considerar que desmobilização e mobilização seriam duas faces de uma mesma moeda, o que desembocaria, necessariamente, em lutas e conflitos abertos de grandes proporções. Isso comprometeria a análise, que assumiria uma postura teleológica, como se as lutas fossem um resultado inexorável, pre- 
viamente definido. Trata-se de atentar à desmobilização e às formas de resistência cotidiana para melhor entender os momentos de lutas mais visíveis, abertas, mas também compreender o porquê da opção muito frequente e comum de não lutar, de não resistir e aceitar a sujeição.

\section{NotAS}

1 A região serrana é formada pelos municípios conhecidos em 2015 como Bom Jardim, Cantagalo, Carmo, Cordeiro, Duas Barras, Nova Friburgo, Trajano de Moraes, Santa Maria Madalena, São Sebastião do Alto e Sumidouro. Na pesquisa foram utilizadas fontes variadas como depoimentos orais, processos administrativos e judiciais, documentação cartorial (partilhas, testamentos e inventários) e eclesiástica (assentamentos de batismo e matrimônio), dados de censos demográficos e agropecuários do IBGE, acervos particulares, documentos das entidades dos trabalhadores rurais, levantamentos em periódicos e nos arquivos da polícia (cf. Dezemone, 2008 a).

2 Não cabe aqui discutir a legitimidade da propriedade privada, nem os mecanismos de sua ampliação no século XIX. Cabe apenas ressaltar que se trata de uma construção social e, por isso mesmo, objeto de conflitos.

3 Censos Demográficos, IBGE, 1872, 1890, 1892, 1910 e 1920.

4 Agradeço a Márcia Motta (UFF), que gentilmente cedeu as reportagens datilografadas.

5 Esse é um tema instigante, complexo, que não pode ser satisfatoriamente desenvolvido no escopo reduzido deste artigo. Para maiores informações, ver Dezemone (2008 a, cap. 1). Os casamentos com 3 e 4 casais no mesmo dia não foram contabilizados.

6 Depoimento do Sr. Juscelino Cândido da Silva (Sr. Binó) em 10/09/2001. Acervo do CPDA-UFRRJ. Pesquisa Assentamentos rurais, caixa Santo Inácio. Optou-se neste artigo por priorizar trechos dessa entrevista, embora as representações apareçam em depoimentos de vários ex-colonos. Realizadas para a pesquisa Assentamentos rurais em perspectiva comparada, projeto que reuniu pesquisadores da UFRRJ-CPDA, FGV, UFF e EHESS-Paris, as entrevistas procuravam recuperar os processos constitutivos de quatro assentamentos rurais no estado do Rio de Janeiro, entre os quais Santo Inácio, na região serrana. 0 autor participou dessas entrevistas (cf. Dezemone, 2008 a).

7 Depoimento do Sr. Álvaro Pereira (Sr. Roldão), em 09/09/2001. Acervo do CPDA-UFRRJ, Pesquisa Assentamentos rurais, caixa Santo Inácio.

8 Censos Agropecuários e Censos Demográficos, IBGE, 1920, 1940, 1950 e 1960.

9 Caderneta de colono da década de 1930. Acervo da fazenda Santo Inácio.

10 Censos Agropecuários, IBGE, 1940, 1950, 1960 e 1970.

11 Enquanto a média do estado foi de $+2,97$, tiveram variação negativa, após Trajano de Moraes com $-2,14 \%$, todos municípios limítrofes: Duas Barras -1,88\%; Santa Maria Madalena -1,68\%; São Sebastião do Alto -1,53\%; e Bom Jardim -0,92\%. \%. Dados do IBGE.

12 APERJ, Fundo Polícias Políticas no Rio de Janeiro, A rota da subversão, prontuário n. 33.634, p. 160-161.

13 Ato histórico de fundação do Sindicato Rural de Trajano de Moraes. Gestão 2001, sede do STR de Trajano de Moraes. 


\section{REFERÊNCIAS BIBLIOGRÁFICAS}

ALVES FILHO, Ivan. Brasil: 500 anos em documentos. Rio de Janeiro: Mauad, 1999.

CARDOSO, Ciro. Escravo ou camponês? O protocampesinato negro nas Américas. Rio de Janeiro: Brasiliense, 1987.

DEAN, Warren. Rio Claro: um sistema brasileiro de grande lavoura. Rio de Janeiro: Paz e Terra, 1977.

DEZEMONE, Marcus. Revoluções camponesas no século XX. In: TEIXEIRA DA SILVA, F. C. (org.). O século sombrio. Rio de Janeiro: Campus/Elsevier, 2004, p. 71-110.

Do cativeiro à reforma agrária: colonato, direitos e conflitos (1872-1987). Tese (Doutorado) - PPGH-UFF, Niterói, 2008 a.

. Legislação social e apropriação camponesa: Vargas e os movimentos rurais. Estudos Históricos, Rio de Janeiro, v. 21, n. 42, p. 220-240, 2008 b.

FAUSTO, Boris. Expansão do café e crise cafeeira. In FAUSTO, Boris (org.). História geral da civilização brasileira, tomo III, vol. 2. São Paulo: Difel, 1986.

GARCIA, Afrânio; PALMEIRA, Moacir. Rastros de casas grandes e de senzalas: transformações sociais no mundo rural brasileiro. In: SACHS, I.; WILHEIM, J.; PINHEIRO, P. S. (Org.). Brasil: um século de transformações. São Paulo: Cia. das Letras, 2001, p. 38-77.

GRYNSZPAN, Mario; DEZEMONE, Marcus. As esquerdas e a descoberta do campo brasileiro: Ligas Camponesas, comunistas e católicos (1950-1964). In: FERREIRA, J.; AARÃO REIS, D. (Org.). As esquerdas no Brasil (1945-1964). Rio de Janeiro: Civilização Brasileira, 2007, v. 2, p. 209-236.

HEREDIA, Beatriz. Morada da vida. Rio de Janeiro: Paz e Terra, 1979.

LACERDA WERNECK, Francisco Peixoto de. Memória sobre a fundação de uma fazenda na Província do Rio de Janeiro. Brasília: Senado Federal/ Rio de Janeiro: Casa de Rui Barbosa, 1985 [1847].

MARTINS, José de Souza. O cativeiro da terra. São Paulo: Hucitec, 1979.

MATTOS, Hebe. Das cores do silêncio: os significados da liberdade no Sudeste escravista - Brasil, séc. XIX. Rio de Janeiro: Nova Fronteira, 1998.

MELO, Hildete Pereira de. 0 café e a economia fluminense: 1889/1920. In: SILVA, S.; SZMRECSÁNYI, T. (Org.). História econômica da Primeira República. 2a ed. São Paulo: EDUSP/ Imprensa Oficial, 1996, p. 215-234.

MOORE JR., Barrington. Injustiça: as bases sociais da obediência e da revolta. São Paulo: Brasiliense, 1987.

NEVES, Delma Pessanha. Formas tuteladas de condição camponesa: colonato e morada na agroindústria exportadora. In: ; MORAES, M. A. (Org.). Processos de constituição e reprodução do campesinato no Brasil: formas tuteladas de condição camponesa. São Paulo/Brasília: UNESP/NEAD, v. 1, p. 137-161, 2008.

PALMEIRA, Moacir. Casa e trabalho: notas sobre as relações sociais na plantation tradicional. Contraponto, n. 2, p. 103-114, dez. 1977.

Desmobilização e conflito: relações entre trabalhadores e patrões na agroindústria pernambucana.

Revista de Cultura e Política, CEDEC, v.1, p. 41-55, ago. 1979. 
REIS, João José; SILVA, Eduardo. Negociação e conflito. A resistência negra no Brasil escravista. São Paulo: Companhia das Letras, 1988.

REVEL, Jacques. Jogos de escala. A experiência da microanálise. Rio de Janeiro: Ed. FGV, 1998.

RIOS, Ana Lugão; MATTOS, Hebe. Memórias do cativeiro. Rio de Janeiro: Civilização Brasileira, 2005.

SCOTT, James. Everyday forms of peasant resistance. Journal of Peasant Studies, v. 13, n. 2, jan. 1986, p. 5-35.

SLENES, Robert. Na senzala, uma flor. Esperanças e recordações na formação da família escrava. Brasil, sudeste, século XIX. Rio de Janeiro: Nova Fronteira, 1999.

STEIN, Stanley. Vassouras: um município brasileiro do café, 1850-1900. Rio de Janeiro: Nova Fronteira, 1990. STOLCKE, Verena. Cafeicultura - homens, mulheres e capital (1850-1980). São Paulo: Brasiliense, 1986.

; HALL, Michael. A introdução do trabalho livre nas fazendas de café de São Paulo. Revista Brasileira de História, São Paulo, n. 6, p. 80-120, 1983. 